\title{
A representação social de negros e das cotas raciais em notícias da mídia on-line sobre candidato ao concurso do Itamaraty ${ }^{1}$
}

\author{
Francisco Higo Amorim ${ }^{2}$ \\ Mara Lúcia Castilho ${ }^{3}$
}

\begin{abstract}
Resumo: Esta pesquisa busca analisar a representação dos negros e das cotas raciais em concursos públicos no Brasil a partir dos pressupostos da Análise de Discurso Crítica (ADC). Para isso, foram selecionadas cinco notícias veiculadas em 2013 e 2015 sobre uma possível fraude no sistema de cotas de concursos públicos do Itamaraty. Os resultados mostram que os negros são representados como pobres e, portanto, como sujeitos que não têm profissões de prestígio. O discurso da mídia sobre a participação de negros em concursos públicos por meio de cotas raciais gerou, na sociedade, repúdio às cotas raciais e, consequentemente, aos negros.

Palavras-chave: Análise do discurso crítica. Representações sociais. Cotas raciais.
\end{abstract}

Abstract: This article aims to analyze the representations of blacks and racial quotas in public competitions in Brazil from theoretical assumptions of Critical Discourses Analyses. For this, were selected five news published in the years 2013 and 2015 regarding a possible fraud in the quotas system in the public competitions of Itamaraty. The results show that black people are represented as poor's and, therefore, as people which do not have prestigious professions. The media discourse about the black participation in public tenders through racial quotas systems brought to the society repudiation the quotas and blacks.

Key words: Critical discourses analysis. Social representations. Quotas systems.

Resumen: Esta investigación analiza la representatividad de los negros y de las cuotas raciales en oposiciones públicas en Brasil a partir del Análisis de Discurso Crítico (ADC). Para ello, se seleccionaron cinco noticias transmitidas en 2013 y 2015 sobre un posible fraude en el sistema de cuotas de oposiciones públicas del Palácio de Relaciones Internacionales, el Itamaraty. Los resultados muestran que los negros son representados como pobres y como personas que no tienen profesiones de prestigio. El discurso sobre la participación de negros en oposiciones públicas através de cuotas raciales generó, en la sociedad, repudio a las cuotas raciales y a los negros.

Palabras clave: Análise de discurso critica. Representaciones sociales. Cuotas raciales.

\footnotetext{
${ }^{1}$ Este estudo é resultado de pesquisa de Programa de Iniciação Científica, financiada pela Fundação de Apoio à Pesquisa do Distrito Federal (FAP - DF).

${ }^{2}$ Graduando em letras inglês pelo Instituto Federal de Brasília (IFB) - campus Riacho Fundo.

${ }^{3}$ Doutora em Linguística pela Universidade de Brasília e docente pelo Instituto Federal de Brasília (IFB) - campus Riacho Fundo.
} 


\section{Introdução}

Os principais veículos da mídia têm papel fundamental na transformação ou manutenção de ideologias por meio da representação de objetos e de atores sociais em seus discursos. Essas representações podem influenciar a maneira como a sociedade passa a enxergar as pessoas, os fatos e os objetos, incluindo-as ou rejeitando-as.

Constantemente, ouvimos a mídia publicar notícias e reportagens sobre as Políticas de Ações Afirmativas (PAA) para inclusão dos excluídos socialmente, como, por exemplo, os negros. Uma das formas de compreendermos como se dá a representação dessas políticas e dos negros é por meio da análise do discurso veiculado pela mídia. Nesse sentido, esta pesquisa, fundamentada na Análise de Discurso Crítica (ADC), busca compreender de que maneira os negros e as PAA são representados socialmente no discurso da mídia on-line, quando da divulgação da participação de um candidato autodeclarado cotista, utilizando os critérios raciais, nos concursos do Itamaraty, nos anos de 2013 e 2015. Segundo a mídia, esse candidato foi tido como uma pessoa branca tentando fraudar o sistema de cotas.

A análise de como o discurso da mídia contribui para manter, reproduzir ou transformar ideologias e crenças tem como base o aporte teórico-metodológico de Fairclough (2001), para quem a representação social dos atores sociais e dos objetos pode ser desvendada a partir da análise do discurso que circula nos veículos de comunicação. Para tanto, a análise dos textos foi realizada com base na Gramática Sistêmico Funcional (GSF) (HALLIDAY e MATHIESSEN, 2004), que "busca identificar as estruturas da linguagem específica que contribuem para o significado de um texto" (FUZER; CABRAL, 2014, p. 19); e nos modos de operação da ideologia de Thompson (1995) para compreender as formas simbólicas de se estabelecer e sustentar relações de dominação pela representação social dos negros e da PAA.

Dessa forma, serão analisadas notícias veiculadas em 2013 e 2015 sobre o candidato autodeclarado negro no concurso do Itamaraty nesses dois anos, com a finalidade de mostrar a representação social dos negros e das PAA nessas notícias a partir do contexto sócio-histórico da institucionalização destas no Brasil. 


\section{Contexto das Políticas de Ações Afirmativas para negros no Brasil}

O termo ação afirmativa surgiu nos Estados Unidos, nos anos 1960, com a reivindicação de direitos civis para os negros, quando as leis segregacionistas começavam a ser eliminadas (MOEHLECKE, 2002, p. 197). Apesar dessas políticas serem conhecidas nos EUA, esse não foi o primeiro país a aplicar PAA para inserir grupos de pessoas marginalizadas na sociedade. Entretanto, "dada a grande influência dos Estados Unidos no Brasil, o termo ações afirmativas passou a ser usado também entre nós, em geral para qualificar a discussão sobre políticas de inclusão com o argumento de que as cotas são um tipo, entre vários, de ações afirmativas" (CARVALHO, 2016, p. 16).

No Brasil, a ideia de PAA passou a se intensificar após anos de discussões até ganhar mais visibilidade, em 1995, com a Marcha de Zumbi Contra o Racismo, pela Cidadania e a Vida. Esse ato foi organizado pelo movimento social negro, que levou militantes de todo o país à Brasília para cobrar políticas públicas de reversão do status quo das pessoas negras, com a finalidade de exigir mudanças na legislação e diminuir as desigualdades raciais. Como resultado dessa manifestação, em 1996, em um seminário que discutia políticas para grupos discriminados racialmente, o então presidente da república, Fernando Henrique Cardoso, assumiu publicamente que o Brasil era um país racista.

No decorrer da primeira década do ano 2000, várias PAA foram implementadas em nosso país e, assim, discussões na mídia sobre esse tema passaram a fazer parte do cotidiano dos brasileiros. Dentre as discussões, questionou-se a constitucionalidade das políticas de cotas raciais nas universidades. Por serem autônomas, algumas adotaram essa política de inclusão antes mesmo de a lei ser sancionada. As discussões sobre a constitucionalidade das cotas raciais para as universidades se encerrou quando o STF (Supremo Tribunal Federal), unanimemente, em 2012, julgou-as constitucionais.

Nessa decisão ficou esclarecido que as PAA têm enfoque do termo raça no sentido social, pois ela não se baseia numa realidade científica do ponto de vista genético ou biológico. De acordo com Bonnafous e Fiala (1992), o conceito de raça 
representa uma realidade social, [...] que remete a uma organização perceptiva comum de referências à diversidade humana. Sendo assim, neste artigo, a palavra raça fundamenta-se no conceito social, que, no Brasil, pelo contexto da miscigenação, é um conceito ligado ao fenótipo.

Entretanto, as características fenotípicas não podem ser ignoradas entre as classes sociais na composição do país, pois representam, ainda hoje, as consequências da sociedade escravagista, como pode ser observado nos resultados da pesquisa realizada pelo IPEA em 2014:

[...] a distribuição de negros é superior em empregado sem carteira, empregado doméstico, conta própria não contribuinte, não remunerado e trabalhador para próprio consumo. Os trabalhadores brancos apresentam maior concentração na atividade de empregador: 5,4\% dos brancos ocupados estão nesta categoria, enquanto apenas $2,3 \%$ dos negros ocupados se dedicam a esta atividade (IPEA, 2014, p. 27).

As questões raciais no Brasil passam pelo entendimento sociológico de Gilberto Freyre (2006), para quem o país manteve sua miscigenação de forma pacífica e harmoniosa em comparação com outros países. Segundo esse autor, "híbrida desde o início, a sociedade brasileira é de todas da América a que se constituiu mais harmoniosamente quanto às relações de raça [...]” (FREYRE, 2006, p. 160). Por outro lado, em Fernandes (2008) tem-se o entendimento de que a ideia de democracia racial é um mito e que um de seus efeitos foi, também, a utilidade prática desse pensamento em que se

isentou o 'branco' de qualquer obrigação, responsabilidade ou solidariedade morais, de alcance social e de natureza coletiva, perante os efeitos sociopáticos da espoliação abolicionista e da deterioração progressiva da situação socioeconômica do negro e do mulato (FERNANDES, 2008, p. 311).

Assim, para Fernandes (2008), o mito serviu, também, dentre outras coisas, para desresponsabilizar o branco no decorrer de sua história no Brasil, difundindo uma consciência falsa sobre o pensamento racial brasileiro. 
É nesse contexto que as leis de PAA com recorte racial foram implementadas no Brasil. Entretanto, um dos desafios das leis, tanto a de no $12.711 / 12^{4}$ quanto a de no 12.990/14 $4^{5}$, dentre outras políticas com recorte racial, é como distinguir a miscigenação que compõe a sociedade brasileira. Em ambas essas leis, os candidatos que optarem por concorrer pelas vagas reservadas para pretos e pardos devem se autodeclarar como tais.

Por um lado, a Lei no 12.990/14 utiliza o mesmo critério do IBGE (Instituto Brasileiro de Geografia e Pesquisa):

\begin{abstract}
"Art. $2^{\circ}$. Poderão concorrer às vagas reservadas a candidatos negros aqueles que se autodeclararem pretos ou pardos no ato da inscrição no concurso público, conforme o quesito cor ou raça utilizado pela Fundação Instituto Brasileiro de Geografia e Estatística - IBGE" (BRASIL, 2014, grifo nosso).
\end{abstract}

Por outro, esse mesmo órgão usa somente a autodeclaração como critério para sistematização e avaliação da cor dos indivíduos, não existindo outro dispositivo para essa verificação. Assim, ao mesmo tempo em que as cotas raciais se justificam no Brasil pelas desigualdades sociais entre as raças, o país também é formado por uma forte miscigenação e hibridização entre os povos, o que dificulta identificar quem faz jus a participar das PAA por ser parte dessa camada social excluída e quem não faz.

Outro desafio das PAA se dá na divergência dos dados coletados a partir desse critério de verificação da raça, pois, na literatura especializada, é consensual que a autodeclaração e a heteroclassificação, em pesquisas de levantamento de dados, provocam divergências. A heteroclassificação, conforme Petruccelli (2014, p. 44), é a “atribuição de uma categoria étnico-racial a alguém, escolhida por outra pessoa”. Nesse sentido, a ancestralidade não é tão determinante e, sim, os elementos de caracterização fenotípica dos indivíduos. Assim, o indivíduo é classificado, na sociedade, a partir da cor dos olhos, da cor da pele e da caraterística dos fios de cabelo, isto é, de seu fenótipo, ainda que o caráter genotípico não seja determinante para isso,

\footnotetext{
${ }^{4}$ Lei que "dispõe sobre o ingresso nas universidades federais e nas instituições federais de ensino técnico de nível médio e dá outras providências" (BRASIL, 2012), também conhecida como lei de cotas nas universidades.

${ }^{5}$ Lei que "reserva aos negros $20 \%$ (vinte por cento) das vagas oferecidas nos concursos públicos para provimento de cargos efetivos e empregos públicos no âmbito da administração pública federal, das autarquias, das fundações públicas, das empresas públicas e das sociedades de economia mista controladas pela União" (BRASIL, 2014).
} 
ao menos no Brasil. Santos, Souza e Sasaki (2013, p. 547) ratificam o entendimento de que a questão racial "não se estrutura em torno do conceito biológico de raça, mas sim a partir de um dado universal inegável, o fenótipo”.

Nas análises das notícias veiculadas pela mídia on-line sobre a autodeclaração do candidato a uma vaga pelas cotas raciais, o fenótipo também aparece como um dos elementos de representação social dos negros, conforme será demonstrado posteriormente.

\section{Políticas de Ações Afirmativas no Itamaraty}

Seguindo o critério da autodeclaração, o Itamaraty já utilizava PAA antes da promulgação da Lei no 12.990 , de 09 de junho de 2014, tanto para reserva de vagas como para candidatura a bolsa de estudos. No edital do concurso de 2013 dessa instituição, a política de inclusão, conforme verificada no item 5.4.1.1, é estabelecida pela autodeclaração: "Os candidatos afrodescendentes deverão declarar, no ato da inscrição, em campo apropriado, essa condição, com vistas à aplicação das disposições previstas no subitem 7.6 deste edital" (BRASIL, 2013, p. 14, grifo nosso). Como podemos perceber, a autodeclaração da afro-descendência era o critério para a seleção dos candidatos nesse certame. No entanto, o termo afrodescendente é bastante discutido contemporaneamente, pois, "[...] ao compreender a ideia da África como berço da civilização, tal categoria nos remete à noção de que todos os grupos étnicos poderiam reivindicar a identidade de afrodescendente" (NASCIMENTO; FONSECA, 2013, p. 59).

Nesse sentido, a visível miscigenação ocorrida no Brasil gera dúvidas e, por vezes, má fé de alguns candidatos que se declaram negros ou pardos. O edital, ao usar o termo afrodescendente, não determina com clareza qual grupo étnico é o alvo do recorte a ser inserido em alguns setores da sociedade. O termo afrodescendente “[...] necessita ser devidamente compreendido no contexto nacional e internacional, bem como nos cenários sociais e culturais, locais e regionais, a fim de designar a população de descendentes de africanos nascidos na diáspora” (FONSECA, 2004, p. 70). 
Após a promulgação da Lei no 12.990/14, o concurso desse órgão foi alterado e, em 2015, o edital oferecia $20 \%$ das vagas para negros. Além disso, o termo afrodescendente foi substituído por negro, conforme estabelecido pela Lei. Assim, o item 5.1.2 do edital de 2015 trazia o seguinte texto:

Para concorrer às vagas reservadas, o candidato deverá, no ato da inscrição, optar por concorrer às vagas reservadas aos negros, preenchendo a autodeclaração de que é preto ou pardo, conforme quesito cor ou raça utilizado pela Fundação Instituto Brasileiro de Geografia e Estatística - IBGE (BRASIL, 2015, p. 4, grifo nosso).

Desse modo, para os mais desatentos, o Itamaraty demonstrou ter adotado política afirmativa para inclusão dos negros, no edital do concurso de 2013, mas quando analisado o edital, pôde-se perceber que não houve a adoção dessa política. Pelo edital, foram acrescidas, além do total de vagas para a classificação geral na primeira etapa do certame, dez vagas para a classificação dos negros, isto é, em vez de cem vagas para classificação na primeira fase, conforme edital, foram classificados cento e dez candidatos, entre eles os declarados negros. Na segunda fase do concurso, esses dez candidatos concorreram às mesmas vagas em igual condição que os demais candidatos não declarados negros. O edital de 2013 não trazia especificação de reservas de uma porcentagem ou quantidade de vagas específica para os negros conforme a Lei no ${ }^{\mathbf{1 2}}$.990/14 passou a determinar. As vagas eram as mesmas para quem havia se declarado negro e para os demais.

\section{Fundamentação teórica}

Segundo Fairclough (2001, p. 91), discurso é "uma prática, não apenas de representação do mundo, mas de significação do mundo, constituindo e construindo o mundo em significado”. Dessa forma, a ADC trata os processos sociais relacionados às transformações pelas quais passa a sociedade contemporânea, em que o discurso é a representação das ideologias presentes nos textos que circulam no cotidiano. Entendese, assim, o discurso como uma prática social, isto é, "um modo de ação, uma forma 
em que as pessoas podem agir sobre o mundo e especialmente sobre os outros, como também um modo de representação" (FAIRCLOUGH, 2001, p. 91).

Nesse sentido, os textos que circulam na mídia no cotidiano veiculam valores e crenças de forma não explícita, muitas vezes, não identificados por seus interlocutores. Esses valores e crenças são ideologias veiculadas como estratégias de manutenção ou de mudança de determinados posicionamentos da sociedade. Conforme Fairclough (2001, p. 117), “As ideologias embutidas nas práticas discursivas são muito eficazes quando se tornam naturalizadas e atingem o status de 'senso comum'”.

Assim, a ADC surgiu com a finalidade de mostrar a relação dialética existente entre o discurso e as práticas sociais com o objetivo de revelar as ideologias presentes nessas práticas. Ainda de acordo com esse mesmo autor

a prática discursiva é constitutiva tanto de maneira convencional como criativa: contribui para reproduzir a sociedade (identidades sociais, relações sociais, sistemas de conhecimento e crença) como é, mas também contribui para transformá-las (FAIRCLOUGH, 2001, p. 92).

Para verificar de que maneira a linguagem pode revelar as ideologias presentes no discurso, foi utilizada a Linguística Sistêmico Funcional (LSF), proposta por Halliday (1994); Halliday e Mathiessen (2004), pois ela auxilia a compreender que a linguagem é realizada nas práticas sociais do cotidiano, indissociável do contexto sociocultural, e se realiza por meio de três metafunções. Essas metafunções da linguagem são as formas de utilizar a língua, que correspondem em compreender a realidade por meio da representação do mundo, através da metafunção ideacional; as formas de utilizar a língua para nos relacionar e interagir com outras pessoas, também com trocas de bens e serviços através da metafunção interpessoal; e, por fim, a organização das informações, com a metafunção textual (HALLIDAY, 2004).

O Sistema de Avaliatividade (MARTIN; WHITE, 2005) possibilitou identificar as realizações léxico-gramaticais que permitem avaliar algo ou alguém no discurso e "vislumbrar, a partir da perspectiva sistêmico-funcional de linguagem, os diferentes recursos utilizados e as possíveis metodologias para a análise de como tais mecanismos ocorrem em língua portuguesa" (VIAN JR, 2010, p. 19). Nesse Sistema, a Atitude é um subsistema que expressa linguisticamente avaliações positivas e negativas sobre as 
pessoas e as coisas. Esse subsistema investiga os recursos semânticos para avaliar o sentimento das pessoas no discurso por meio do Afeto; analisa os recursos semânticos utilizados para Julgamento, que constrói linguisticamente avaliações sobre o comportamento das pessoas; e, por fim, analisa os recursos semânticos de Apreciação, que avalia coisas. Outro subsistema da Avaliatividade encontrado nos textos das notícias foi o Engajamento - posicionamento dialógico que pode expandir ou contrair o discurso, isto é, possibilidade de discordância do discurso. A heteroglossia indica as vozes presentes no discurso para contração ou expansão dialógica. Ao contrair o discurso, o produtor do texto toma uma posição de rejeição a pontos de vistas diferentes. Com o uso de vozes externas, o Endosso, justifica-se o ponto de vista do produtor do texto, sem, contudo, se comprometer com o que está dizendo. Nas notícias analisadas, várias vozes se somaram aos discursos para representar o candidato pelas cotas para negros como branco.

Por fim, para investigar o modo de operação das ideologias no discurso, foi utilizado o aporte teórico metodológico de Thompson (1995), para quem as formas simbólicas da ideologia servem para estabelecer e sustentar relações de dominação sistematicamente assimétricas no discurso. Para esse autor, as estratégias de atuação da ideologia se entrecruzam com as relações de poder. Thompson (1995) aponta cinco modos operandi da ideologia no discurso: Legitimação, que situação de dominação é representada como digna de apoio; Dissimulação, em que representa a situação de dominação de maneira ocultada, negada ou obscurecida; Unificação, diz respeito às relações de dominação que são estabelecidas e sustentadas com a construção de uma unidade, padronização; Fragmentação, isto é, as relações de poder estabelecidas no discurso para representar objetos e pessoas podem ser mantidas de maneira a não incluir determinados grupos em uma coletividade, mas segmentando-os e fragmentando-os como grupo ameaçador; Reificação, que ofusca processos históricos e naturaliza criações sociais e históricas. Nos textos analisados, os modos operandi mais reincidentes são a reificação, com o seu subitem naturalização e a fragmentação, com expurgo do outro.

\section{Análise}


Para analisar o discurso e, consequentemente, a representação da PAA e dos negros na mídia on-line, foram selecionadas cinco notícias veiculadas em 2013 e 2015, sobre a repercussão do mesmo candidato ao Itamaraty nos concursos públicos realizados nesses dois anos, autodeclarado afrodescendente e negro, respectivamente. A partir dessas notícias, foram analisadas as estratégias de operação da ideologia dos veículos de comunicação sobre a representação das PAA e dos negros. Segundo essas notícias, a partir do Endosso da fala de outras pessoas, o candidato autodeclarado negro não apresentava as características fenotípicas correspondentes ao grupo a quem as vagas eram destinadas.

As notícias foram selecionadas por terem tido repercussão negativa sobre os debates da época sobre as PAA. Entre os casos relativos a esses episódios de possíveis brancos se candidatando a vagas de cotistas negros em concursos e vestibulares, o caso Abramovic foi o que mais se destacou por ter sido foco da mídia em dois anos distintos. Assim, foram selecionadas, da mídia on-line, duas notícias veiculadas em 2013 e três, em 2015 sobre esse fato. Portanto, duas antes da Lei no 12.990/14 ser sancionada e duas depois de a lei entrar em vigor. As notícias de 2013 são dos jornais on-line Veja e O Globo, ambas datadas de 11 de setembro, sendo identificadas, ao longo das análises, como N1 e N2, respectivamente. Já as notícias do ano de 2015 são dos jornais Correio Web, de 23 de julho; Exame, de 24 de julho; O Globo, de 24 de agosto, identificadas, ao longo das análises, como $\mathrm{N}_{3}, \mathrm{~N}_{4}$ e $\mathrm{N}_{5}$, respectivamente.

Primeiramente, serão descritas as análises da representação das PAA e, por fim, serão descritas as análises da representação do negro nas notícias veiculadas na mídia on-line através da representação de um candidato considerado branco que se declarou afrodescendente, portanto cotista.

\section{Representação das Políticas de Ações Afirmativas}


A análise da representação das PAA no discurso das notícias selecionadas nesta pesquisa foi realizada com base em Thompson (1995), conforme esclarecido anteriormente. Nesse sentido, buscou-se identificar de que maneira essa representação foi organizada textualmente, com base em Halliday (1994), Halliday e Mathiessen (2004) e Martin e White (2005). Nos exemplos de 1 a 4, os termos em negrito destacam os processos e os nomes utilizados para representar a PAA nas notícias veiculadas pela mídia on-line:

1. N2: A questão racial está gerando novos atritos dentro do Ministério das Relações Exteriores.

2. N2: E desta vez a polêmica é no processo seletivo para o Instituto Rio Branco, que seleciona os candidatos que servirão nos quadros da diplomacia brasileira.

3. N2: A questão racial é delicada no Itamaraty.

4. N3: A discussão sobre o sistema de cotas raciais para ingresso no funcionalismo está longe do fim.

De acordo com Martin e White (2005), uma das estratégias discursivas utilizadas para demonstrar avaliações positivas e negativas sobre as pessoas e as coisas no Sistema de Avaliatividade são as realizações semânticas encontradas no subsistema Atitude, entre elas, a Apreciação. Essa categoria do subsistema Atitude possibilita a identificação das avaliações sobre as coisas e os objetos. Uma das realizações dessa categoria é o uso de epítetos que indicam apreciação positiva ou negativa.

Nos exemplos de 1 a 4, encontramos a presença dos epítetos negativos como, por exemplo: polêmico, delicado, longe do fim, todos relacionados à questão racial, isto é, às PAA. Essa realização semântica expressa a avaliação negativa da mídia sobre essas políticas. O processo relacional utilizado na construção dos enunciados é ser, que atribui à Lei e à PAA atributos negativos. As orações relacionais atributivas são utilizadas para representar pessoas e coisas (HALLIDAY, 1994; HALLIDAY e MATHIESSEN, 2004). No caso dos exemplos 1 a 4, há sempre um Portador e um Atributo, caracterizando-o por meio de características comuns a membros de uma classe ou grupo, a fim de distingui-las das demais, isto é, há, pelo menos, dois grupos 
distintos sendo representados, os que se inserem nas cotas e aqueles que estão fora dela, levando o leitor a interpretar que o grupo representado pelas cotas raciais é uma ameaça ao grupo distinto dela.

Os epítetos encontrados no discurso da mídia on-line - exemplos de 1 a 4 demonstram, conforme Thompson (1995, p. 87), a estratégia de operação da ideologia para estabelecer relação de poder por meio da construção de um inimigo, representando-o como um mal a ser combatido, isto é, como um grupo diferente dos demais, que traz ameaça à ordem estabelecida. Essa estratégia, segundo Thompson (1995), caracteriza o expurgo do outro, ou seja, o discurso da mídia nas notícias analisadas busca apresentar a PAA como uma ameaça a ser combatida pela sociedade, levando os indivíduos a resistirem coletivamente a esse mal que visa tirar o sossego das pessoas. Os termos “conflito”, “polêmico", “delicado” fazem parte de um repertório semântico de significado negativo, conforme Martin e White (2005). Nesse sentido, há uma tentativa da mídia de manutenção da crença de que a inclusão de negros é uma ameaça à ordem estabelecida. Dessa forma, segundo a mídia, se as PAA para inclusão de negros forem efetivadas, elas podem causar problemas à sociedade. Por considerar que os dados levantados pelo governo e pelos movimentos negros não passam de pontos de vista ideológicos ${ }^{6}$, a discussão sobre as cotas raciais, conforme exemplo 4, para a mídia, é uma discussão indesejável e sem fim próximo.

Nos exemplos 5 a 8, encontramos marcações, em negrito, que demonstram que a lei não é necessária em razão de ser direcionada a uma pequena parcela de pessoas e, por isso, não é efetiva, isto é, tem lacunas. Já os destaques em itálico nos exemplos 6 e 7 demonstram a avaliação da mídia sobre os supostos candidatos fraudadores:

5. N3: A lei no 12.990/14, que reserva 20\% das vagas para cargos e empregos em órgão da União, tem lacunas que não ajudam a reduzir a disparidade entre negros e brancos na administração pública.

\footnotetext{
${ }^{6}$ Durante a década passada, Ali Kamel ganhou destaque emitindo artigos de opiniões em suas diversas publicações se posicionando contrário à adoção de cotas raciais nas universidades. Em um de seus textos, podemos verificar a seguinte citação: "Há uma semana, o IBGE divulgou pesquisa sobre emprego e raça, e os jornais concluíram que os dados 'comprovavam' que os negros são discriminados no mercado de trabalho. Foi um erro, um passo além do que os números permitiam dizer" (KAMEL, 2004).
} 
6. N3: Como a legislação estabelece a autodeclaração da raça na hora de se inscrever, muitos candidatos se aproveitam da brecha para tentar entrar no serviço público.

7. N3: O candidato pode não ser o único a se aproveitar da lacuna da lei.

8. N3: Como as inscrições para as vagas de cota costumam ser em menor número, os interessados encontram menos concorrência do que enfrentariam no sistema amplo.

As palavras brecha e lacunas encontradas nos exemplos de 5 a 7 demonstram uma avaliação negativa da lei e transmitem ao leitor a sensação de que os legisladores não foram precisos na elaboração do texto legal e, por isso, confirmam a ameaça que as PAA são à sociedade. Sendo assim, a Lei no 12.900/14 é representada como uma legislação que tem espaços a serem preenchidos e, enquanto isso, invasores estão se infiltrando.

No discurso da mídia, é como se a legislação não previsse algo que já está no senso comum do cotidiano do brasileiro, isto é, a crença (ideologia) da sociedade de que esse é mais um fator que contribuirá para ratificar a suposta desonestidade do brasileiro, de alguém que sempre tenta levar vantagens. Nos trechos em itálico, nos exemplos de 6 e 7, o processo que estabelece relação entre as PAA e os candidatos é aproveitar, levando, mais uma vez, o leitor a crer que essas políticas são ameaçadoras. Os candidatos são avaliados como aproveitadores de algo que, supostamente, não foi previsto, por ter brechas na lei. E, por essa razão, os candidatos brancos que optam pelo sistema de cotas são representados como pessoas de má fé. Mais uma vez, a estratégia de operação da ideologia do expurgo do outro (THOMPSON, 1995) é identificada no discurso da mídia, pois, ora o grupo a ser excluído são os negros, ora os brancos desonestos. Nesse sentido, as PAA, mais uma vez, são tidas como ameaçadoras.

A lei também é representada como uma legislação pouco efetiva, que não ajuda a reduzir a disparidade entre negros e brancos, poucos candidatos optam pelo sistema de cotas e, por essa razão, ela se torna um caminho mais fácil para a aprovação dos candidatos aproveitadores. No exemplo 5 (A Lei no $12.990 / 14$, que reserva $20 \%$ das vagas para cargos e empregos em órgão da União, tem lacunas que não ajudam a 
reduzir a disparidade entre negros e brancos na administração pública), podemos verificar no trecho em itálico que a disparidade entre negros e brancos na sociedade que a lei tenta reverter existe apenas na administração pública. Além disso, busca persuadir o leitor de que a procura dos candidatos por cotas é baixa, como no exemplo 8 (as vagas de cota costumam ser em menor número, os interessados encontram menos concorrência do que enfrentariam no sistema amplo), e que isso chama a atenção de candidatos de má fé. Com isso, a mídia apresenta a lei como algo negativo, pois, com ela se tem muitos problemas que antes não existiam.

A representação das PAA nas notícias divulgadas no ano de 2013 também eram cota para negro, sistema de cotas, cota para afrodescendente, benefício e reserva adicional, conforme podemos constatar nos seguintes exemplos:

9. Ni: Itamaraty analisa caso de candidato branco aprovado nas cotas para negros.

10. N1: O ministério não adiantou se o candidato será retirado da disputa ou se haverá alguma mudança no sistema de cotas do concurso.

11. N2: Dentre os 10 nomes de candidatos aprovados na primeira fase do concurso dentro das cotas para afrodescendentes [...]

12. N2: Para concorrer dentro das cotas, basta que o candidato se declare "afrodescendente".

Essas representações, em negrito nos exemplos 9 a 12, conforme a LSF (Halliday, 1994) são Circunstâncias, que "adicionam significados à oração pela descrição do contexto em que o processo se realiza" (FUZER; CABRAL, 2014, p. 53). As Circunstâncias encontradas, nesses exemplos, revelam um lugar, como nas contrações da preposição em com os artigos o e $a$ - nas e no -, nos exemplos 9 e 10, que, semanticamente, produzem ideia de que as cotas raciais estão dentro de algo ou em algum lugar. Nos exemplos 11 e 12, esse lugar é expresso pelo advérbio dentro. Nesse sentido, as cotas raciais são representadas como uma Circunstância de lugar, ou uma espécie de caminho, por onde se tem um atalho para a aprovação de maneira facilitada em que muitas pessoas estariam usufruindo, ou se aproveitando desse caminho, 
visando a aprovação, ao contrário daqueles que estão indo pelo caminho mais difícil, os que estão fora das cotas.

Além disso, antes da Lei no 12.990, de 2014, as PAA eram também representadas como um benefício dado a um grupo diferenciado, conforme demonstram os exemplos 13 e 14:

13. N2: O benefício vale para a primeira fase do processo seletivo [...].

14. N1: Na primeira fase, as cotas reservam um adicional de dez vagas para afrodescendentes $[\ldots]$.

Nesses dois exemplos, verificamos que as cotas raciais, antes da promulgação da lei, são representadas como benefício e reserva de vagas. Além disso, o uso do processo material reservar, como observado no exemplo 14, significa que "as orações em que se desdobram processos materiais são definidas como orações de 'fazer e acontecer', porque estabelecem uma quantidade de mudança no fluxo de eventos” (FUZER; CABRAL, 2014, p. 46). Sendo assim, a mudança, então, ocorre por conta de um Ator, que deposita energias nesse processo. Nesse caso, o ator é cotas raciais que reservam algo para alguém, que são as vagas aos negros. Essas representações ratificam o senso comum e buscam fazer com que os leitores que não fazem parte desse 'grupo beneficiado' se voltem contra o suposto grupo a ser expurgado, pois recebem benefícios do governo sem se esforçarem para tal, pois eles têm vagas reservadas, diferentemente dos demais candidatos - aqueles que não recebem o benefício, conforme representado no exemplo 13. A expressão reservam um adicional juntamente com a representação benefício colabora para a estratégia de operação ideológica contra as cotas raciais, como se a PAA fosse um mal a ser combatido, pois atua como facilitador de um grupo que não pode se infiltrar na sociedade, pois, conforme vimos anteriormente, está gerando temas desconfortáveis e delicados.

\section{A representação dos negros}


A análise linguística das notícias veiculadas na mídia on-line revelou que a representação do negro é construída a partir das características atribuídas ao candidato não negro. Como vimos anteriormente, a mídia busca produzir no leitor o entendimento de que a legislação da PAA é frágil. Com isso, o candidato declarado negro no concurso do Itamaraty é considerado um suposto caso de má fé, pois não apresenta características fenotípicas e sociais dos negros, uma vez que possui olhos verdes, estudou em escola particular e mora em bairro nobre da cidade do Rio de Janeiro.

Conforme Thompson (1995), outra estratégia de operação da ideologia é realizada por meio da Reificação, isto é, as relações de poder são estabelecidas por meio de uma situação histórica, natural, atemporal. Entre os processos de realização desse modo de operação da ideologia, temos a Naturalização, que, para Thompson (1995), é uma estratégia de "criação social e histórica tratada como acontecimento natural, ou como um resultado inevitável" (2008, p. 88). Encontramos, no discurso da mídia, por meio do Endosso de outras vozes, a tentativa de transformar as características fenotípicas e sociais, naturalizadas na sociedade brasileira como sendo naturais da comunidade negra, isto é, negro é pobre, possui olhos castanho escuro, não estuda em escolas privadas e mora em bairros de periferia.

A análise do discurso da mídia demonstrou essa naturalização da condição do negro na sociedade. Ao mencionar as características do candidato declarado negro no concurso do Itamaraty, fazendo uso das vozes de outras pessoas, podemos verificar que sua representação é o oposto da do negro na sociedade. O candidato representado é o que os negros não são, de acordo com as ideologias mantidas sobre essa fração da sociedade. Além das questões sociais e econômicas naturalizadas como não sendo pertinentes ao negro - rico, morador de bairro nobre, estudante de escola privada -, o candidato é descrito como branco e de olhos verdes, conforme exemplos de 15 a 17 , características fenotípicas não encontradas em negros, segundo o senso comum:

15. N1: Mathias Abramovic, de pele e olhos claros, se autodeclarou afrodescendente e passou de fase na seleção para Instituto Rio Branco.

16. N1: Fotos da rede social de Abramovic mostram que ele tem pele e olhos claros. 
17. N2: Segundo pessoas que prestaram o concurso deste ano, Mathias é branco de olhos verdes.

Nesses exemplos (15 a 17), encontramos que o candidato é supostamente fraudulento em razão de ter pele e olhos claros, ser branco de olhos verdes. Todavia, a crença de que negro não tem olhos verdes e claros é naturalizada pelo discurso da mídia. A crença naturalizada pelo senso comum é que o fenótipo do negro, supostamente, no degradê de cores que compõe a hibridização da sociedade brasileira, possui características não-objetivas e sem precisão, por conta da miscigenação. Dessa forma, busca demonstrar que é inquestionável o fato do candidato não pertencer ao grupo daqueles que podem optar pelas cotas raciais. No exemplo 15, o processo verbal é omitido a fim de dar ênfase às características fenotípicas do candidato. Nos exemplos 16 e 17, o processo relacional (tem; ser) atribui características ao candidato. Esse entendimento sobre as características fenotípicas dos negros confirma, mais uma vez, o entendimento de Hélio Santos (2013), para quem as características perceptíveis pelo fator visível, ou seja, o fenótipo como principal expoente dessa classificação.

Ao representar o candidato autodeclarado negro como o que possui características sociais e físicas de um não-negro, a mídia faz uso de estratégias de Naturalização (THOMPSON, 1995) para defender características do candidato análogas ao padrão de beleza europeu, imposto para todo o mundo através da colonização (CARVALHO, 2008). O candidato, no nosso entendimento, não basta ter somente a pele clara para ser alguém que não pertence ao grupo alvo da PAA, mas ser alguém que tem, também, além de os olhos claros, diploma de graduação em Medicina, reforçando o seu status social. O candidato autodeclarado negro é médico, morador da Zona Sul do Rio e ex-aluno de um colégio privado de alto padrão na capital carioca, conforme demonstram os exemplos abaixo:

18. N4: No centro da discussão, um nome já conhecido: Mathias Abramovic, médico carioca, branco de olhos verdes, que se inscreve mais uma vez como cotista.

19. N5: Abramovic é morador da Zona Sul do Rio e ex-aluno do Colégio Santo Agostinho do Leblon, um dos mais tradicionais do Rio. 
A representação do candidato autodeclarado negro nos exemplos 18 e 19 está voltada para características sociais - médico carioca, morador da Zona Sul do Rio, exaluno do Colégio Santo Agostinho do Leblon - revelando, mais uma vez, segundo o senso comum, que essas características não são pertencentes à comunidade negra brasileira. Essas características sociais demonstram que esses espaços são frequentados por um grupo específico da população, do qual os negros não participam. Assim, enaltecendo a branquitude ${ }^{7}$ do candidato de forma explícita e de sua condição social, chega-se à representação das pessoas negras. Nesse caso, os negros não são médicos, não moram na Zona Sul do Rio, que é um bairro nobre e, por fim, não estudam em colégios privados tradicionais.

Em outros trechos do discurso da mídia, o candidato não-negro é caracterizado como hierarquicamente superior aos cotistas negros em razão de ter quase alcançado uma nota não condizente com um candidato negro, conforme exemplos 20 e 21 :

20. N2: Mathias ficou com nota final 47,50, quase dois pontos a menos que o último candidato aprovado na livre concorrência.

21. N5: Abramovic tirou 46,5 ou seja o,5 pontos abaixo da nota de corte da ampla concorrência.

Mais uma vez, o candidato autodeclarado negro é representado como alguém que não pertence a esse grupo minoritário em razão de não apresentar características condizentes com esse segmento, pois foi capaz de atingir notas altas para uma possível aprovação no concurso, o que não é comum aos negros, conforme representado nesses textos. Nesse sentido, mais uma vez, houve a intenção de naturalizar uma condição dada pelo senso comum, de que a nota de corte das cotas raciais é menor que as da ampla concorrência, isto é, negros não conseguem notas boas, pois não estudaram em

\footnotetext{
7 "A branquitude é entendida como uma posição em que sujeitos que ocupam esta posição foram sistematicamente privilegiados no que diz respeito ao acesso a recursos materiais e simbólicos, gerados inicialmente pelo colonialismo e pelo imperialismo, e que se mantêm e são preservados na contemporaneidade. Portanto, para se entender a branquitude é importante entender de que forma se constroem as estruturas de poder fundamentais, concretas e subjetivas em que as desigualdades raciais se ancoram" (SCHUCMAN, 2014, p. 84).
} 
escolas tradicionais. Nos exemplos 20 e 21, o candidato autodeclarado negro atingiu 47,50 pontos, dois pontos a menos que os demais candidatos (exemplo 20) brancos, ou tirou 46,5, ou seja, o,5 pontos abaixo dos de ampla concorrência, não participantes das cotas.

O Quadro 1 demonstra a representação dos negros nas notícias veiculadas pela mídia on-line a partir da representação do candidato autodeclarado negro no concurso do Itamaraty, tomado como fraudulento por não possuir características sociais e físicas de negros.

Quadro 1 - Representação do negro a partir das características do candidato autodeclarado negro

\begin{tabular}{|l|l|}
\hline $\begin{array}{l}\text { Representação do candidato ao concurso do } \\
\text { Itamaraty autodeclarado negro, considerado } \\
\text { fraudulento por não possuir características de } \\
\text { negro }\end{array}$ & $\begin{array}{l}\text { Representação do negro a partir da } \\
\text { representação do candidato autodeclarado } \\
\text { negro no concurso do Itamaraty }\end{array}$ \\
\hline Pele e olhos claros & $\begin{array}{l}\text { Definição do afrodescendente não é } \\
\text { técnica }\end{array}$ \\
\hline Médico branco & $\begin{array}{l}\text { A profissão de médico não é condizente } \\
\text { com a comunidade negra }\end{array}$ \\
\hline $\begin{array}{l}\text { Abramovic tirou 46,5 ou seja o,5 ponto } \\
\text { abaixo da nota de corte da ampla } \\
\text { concorrência }\end{array}$ & $\begin{array}{l}\text { Negros não conseguem atingir notas altas } \\
\text { em certames por ser inferiores que os } \\
\text { demais candidatos }\end{array}$ \\
\hline Morador da Zona Sul do Rio & $\begin{array}{l}\text { Negro não possui condição financeira e } \\
\text { social para morar na Zona Sul do Rio }\end{array}$ \\
\hline Ex-aluno do Colégio Santo Agostinho & $\begin{array}{l}\text { Negro não possui condição financeira e } \\
\text { social para estudar no colégio Santo } \\
\text { Agostinho }\end{array}$ \\
\hline \multirow{2}{*}{ Fonte: Própria } \\
\hline
\end{tabular}

Fonte: Própria 
O Quadro 1 sistematiza as características impregnadas na sociedade brasileira sobre a representação dos negros pelo senso comum e naturalizadas pela mídia como forma de manter a relação de poder por meio de estratégias de operação de ideologia, conforme Thompson (1995). Para a mídia, é reconhecido e notório de que os negros não possuem características fenotípicas e sociais de igualdade com o suposto candidato fraudulento. Os negros, segundo o discurso da mídia, são pessoas que não possuem condições financeiras que lhes garantam estudar em escolas tradicionais, morar em bairros nobres e ter profissão de prestígio, como ser médico. Além disso, os negros, são representados como pessoas que não alcançam notas satisfatórias em certames de prestígio, como é o caso da carreira diplomática no Itamaraty.

\section{Considerações finais}

A análise do discurso por meio do Sistema de Avaliatividade, da LSF e dos modos de operação das ideologias apontados por Thompson (1995) propiciou uma melhor leitura dos textos sobre as cotas raciais e a representação do negro nos textos das notícias on-line.

Conforme demonstrado, a mídia se posicionou contrária à política de ação afirmativa das cotas raciais em concurso público por meio de estratégias discursivas para manter as relações de poder naturalizadas pelo senso comum de que a PAA é um mal a ser combatido e de que a lei tem brechas que farão com que desonestos se beneficiem dessa proposta. Uma das estratégias mais utilizadas para isso foi o Expurgo do Outro (THOMPSON, 1995).

Foi possível identificar a representação dos negros no discurso da mídia on-line por meio da caracterização fenotípica e social do candidato não-negro, visto como um fraudador beneficiado pela lei, que não previu situações como essa. Os negros foram representados como pessoas que não ocupam lugares de prestígio na sociedade, através da Naturalização (THOMPSON, 1995). Na representação desse candidato, foi identificado no discurso da mídia, que a ideologia da hibridização de raças na sociedade brasileira está presente, mais uma vez, de forma naturalizada pelo Endosso 
(MARTIN; WHITE, 2005) e foi possível verificar que negros são representados como pessoas que não frequentam lugares, situações e contextos sociais de prestígio, demonstrando, assim, que, na sociedade brasileira, existem lugares e ocupações que a presença de negros é baixa ou acontece com pouca frequência, como, por exemplo, ser morador do Leblon e ser médico.

\section{Referências}

BONNAFOUS, S.; FIALA, P. Est-ce que dire la race en présuppose l'existence? Mots: les langages du politique, Lyon: ENS Éditions, n. 33, p. 11-22, déc. 1992. Disponível em: <http://www.persee.fr/web/revues/home/prescript/article/mots_0243-6450_1992_ num_33_1_1734>. Acesso em: maio 2018.

BRASIL. Edital de 17 de junho de 2013. Concurso de admissão à carreira de diplomata. Diário Oficial da União, Brasília, DF, ano 2013, n. 115, 18 de junho de 2013. Seção 3, p. 114. Edital no 1, de 23 de junho de 2015. Concurso de admissão à carreira de diplomata. Diário Oficial da União, Brasília, DF, ano 2015, n. 118, 24 de junho de 2015. Seção 3, p. 81.

Lei № 12.711. 29 de Ago. de 2012. Dispõe sobre o ingresso nas universidades federais e nas instituições federais de ensino técnico de nível médio e dá outras providências. Disponível em: < http://www.planalto.gov.br/ccivil_03/_ato2o112014/2012/lei/l12711.htm>

Lei. 12.990, 9 de junho de 2014. Reserva aos negros 20\% (vinte por cento) das vagas oferecidas nos concursos públicos para provimento de cargos efetivos e empregos públicos no âmbito da administração pública federal, das autarquias, das fundações públicas, das empresas públicas e das sociedades de economia mista controladas pela União. Disponível em: <http://www.planalto.gov.br/ccivil_03/_Ato2011-2014/2014/ Lei/L12990.htm\#art6>

CARVALHO, José Jorge de. A Política de Cotas no Ensino Superior: Ensaio descritivo e analítico do Mapa das Ações Afirmativas no Brasil. Universidade de Brasília, 2016. 
Racismo Fenotípico e Estética da Segunda Pele. Cinética: Revista Eletrônica, Rio de Janeiro, p, 1-14, jan. 2008. Disponível em: <http://www.revistacinetica.com.br/cep/jose_jorge.pdf>. Acesso em: maio 2018.

CORREIO WEB. Candidato que gerou polêmica ao concorrer como cotista, em 2013, volta a se declarar negro. Disponível em: <http://concursos.correioweb.com.br/app/noticias/2015/o7/23/noticiasinterna,35331/ca ndidato-que-gerou-polemica-ao-concorrer-como-cotista-em-2013-volta.shtml>. Acesso em: 22 Jun. 2018.

EXAME. Médico Branco Se Diz Cotista no Itamaraty. Disponível em: <http://exame.abril.com.br/brasil/medico-branco-se-diz-cotista-no-itamaraty/>. Acesso em: 22 Jun. 2018.

EXTRA. Branco de Olhos Verdes é Aprovado por Cotas Raciais no Itamaraty. Disponível em: <http://extra.globo.com/noticias/mundo/branco-de-olhos-verdes-aprovado-porcotas-raciais-no-itamaraty-9908210.html>. Acesso em: 22 Jun. 2018.

FAIRCLOUGH, Norman. Discurso e Mudança Social. Brasília: Editora da UnB, 2001. FERNANDES, Florestan. A Integração do Negro na Sociedade de Classes. Volume I. $3^{\circ}$ ed. São Paulo: Globo, 2008.

FONSECA, D. J. A (re)invenção do cidadão de cor e da cidadania. Cadernos do CEAS, Salvador: Centro de Estudos e Ação Social - CEAS, n. 210, p. 65-83, mar.;abr. 2004.

FREYRE, Gilberto. Casa Grande E Senzala: Formação da família brasileira sob o regime

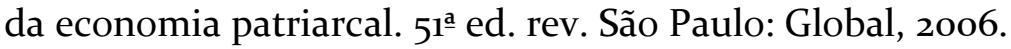

FUZER, Cristiane; CABRAL, S. R. S. Introdução à Gramática Sistêmico-Funcional em Língua Portuguesa. $1^{\mathrm{a}}$. ed. Campinas, SP: Mercado de Letras, 2014.

HALLIDAY, Michael A. K. \& MATHIESSEN, Christian M. I. M. An introduction to functional grammar. 3. ed. Londres: Arnold, 2004.

HALLIDAY, Michael A. K. An introduction to functional grammar. London: hodder, [1984] 1994 .

IPEA. Situação social da população negra por estado. In: Instituto de Pesquisa Econômica Aplicada; Secretaria de Políticas de Promoção da Igualdade Racial. Brasília: IPEA, 2014.

KAMEL, Ali. "Racismo e fraude”. O Globo, 15/o6/2004. 
MARTIN, James R; WHITE, Peter. The language of evaluation: appraisal in English. London: Palgrave, 2005.

MOEHLECKE, Sabrina. Ações Afirmaticas: Histórias e Debates no Brasil. Cadernos de Pesquisa. n. 117, p. 197-217, nov. 2002.

NASCIMENTO, A. S; FONSECA, D. J. Classificações e identidades: Mudanças e Continuidades Nas Definições de Cor ou Raça. In: PETTRUCCELI, José Luis; SABOIA, Ana Lúcia (Org.). Características Étnicos-Raciais da População: Classificações e Identidades. Rio de Janeiro: IBGE, 2013. p. 31-50.

O GLOBO. Candidato de pele branca e olhos verdes volta a ser aprovado por cotas em concurso do Itamaraty. Disponível em: <https://oglobo.globo.com/sociedade/educacao/candidato-de-pele-branca-olhosverdes-volta-ser-aprovado-por-cotas-em-concurso-do-itamaraty-17282261>. Acesso em: 22 jun. 2018.

PETRUCCELLI, José Luis. Autoidentificação, identidade étnico-racial e heteroclassificação. In:___ ; SABOIA, Ana Lucia (Org). Características ÉtnicosRaciais da População: Classificações e Identidades. Rio de Janeiro: IBGE, 2013. p. 31-50. . Raça, identidade, identificação: abordagem histórica conceitual. In: SABOIA, Ana Lucia (Org). Características Étnicos-Raciais da população: Classificações e Identidades. Rio de Janeiro: IBGE, 2013. p. 13-29

SANTOS, Hélio; SOUZA, Marcilene Garcia de; SASAKI, Karen. O subproduto social advindo das cotas raciais na educação superior. Revista Brasileira de Estudos Pedagógicos. (online), Brasília, v. 94, n. 237, p. 542-593, maio/ago. 2013.

SCHUCMAN, Lia Vainer. Sim, nós somos racistas. Psicologia E Sociedade, Universidade de São Paulo, São Paulo, 26(1). 2012, p. 83-94. Disponível em: <http://www.scielo.br/pdf/psoc/v26n1/10.pdf>. Acesso em: 24 de fev. 2018.

THOMPSON, John B. Ideologia e Cultura Moderna: Teoria Social Crítica na era dos Meios de Comunicação de Massa. Petrópolis, RJ: Vozes, 1995.

VEJA. Itamaraty Analisa Caso de Candidato Branco Aprovado nas Cotas para Negros. Disponível em: <http://veja.abril.com.br/politica/itamaraty-analisa-caso-de-candidatobranco-aprovado-nas-cotas-para-negros/>. Acesso em: 22 de jun. 2018.

VIAN JR, Orlando. O Sistema de Avaliatividade e a linguagem da avaliação. In: VIAN JR, Orlando; Souza, Anderson Alves de; ALMEIDA, Fabíola A.S.D.P. A linguagem da 
Revista Investigações Vol. 31, nº 2, Dezembro/2018

avaliação em língua portuguesa: estudos sistêmico-funcionais com base no sistema da avaliatividade. São Carlos: Pedro \& João, 2010.

Recebido em 25/o6/2018.

Aprovado em 10/11/2018. 